\title{
Adsorption treatment of sewage sludge from heavy metals
}

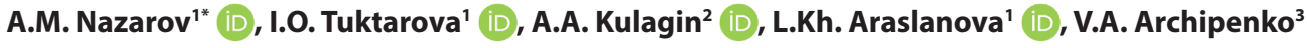 \\ ${ }^{1}$ Ufa State Petroleum Technological University, Ufa, Bashkortostan Republic, Russia \\ ${ }^{2}$ Bashkir State Pedagogical University named after M. Akmulla, Ufa, Bashkortostan Republic, Russia \\ ${ }^{3}$ LUKOIL-Uralnefteprodukt, Ufa, Bashkortostan Republic, Russia
}

* Corresponding author: e-mail: nazarovam1501@gmail.com

\begin{abstract}
Introduction. Because of urban development the volume of municipal and industrial wastewater are growing. Along with them the amount of sewage sludge (SS) also increases. Millions of tons of SS are currently accumulated on the territory of the Russian Federation and contain various pollutants, including heavy metals (HM). In this regard, the search for effective methods of SS treatment from HM is an urgent problem. The main methods of SS treatment are drying, dehydration, thermal methods, UV and microwave wave treatment. These kinds of disinfection eliminates many pathogenic microorganisms, but they are quite expensive and not effective against HM. Reagent methods include SS disinfection with quicklime (CaO). However, decontamination requires large doses (up to 30\%) and it is also ineffective against HM. Humic-mineral reagent are more effective, they are based on crushed caustobiolites, their cleaning capacity from HM is 19-87\%. Methods and materials. The authors have previously shown the effectiveness of wastewater treatment from HM using sorbents based on dolomite, quartzite, and waste from mining and processing plants. Therefore, a method for SS treatment from HM using sorbents based on dolomite, humates, and CS containing $\mathrm{CaCO}_{3}$ and humic compounds was proposed. In this regard, a method was proposed for SS treatment from HM using three types of sorbents based on: 1) waste of thermal power plants (TPP) - conditioned sludge (CS) containing $\mathrm{CaCO}_{3}$ up to $68 \%$ and humic compounds up to $12 \%$ - sorbent 1 (S1); 2) dolomite - Mg and Ca carbonate in a composition with sodium humate (25\%)- sorbent 2 (S2); 3 ) modified dolomite with sodium humate (1\%) - sorbent 3 (S3). Results and discussion. In laboratory experiments, the cleaning capacity of SS was studied using a dolomite-based sorbent modified with humate (1\%). In field tests, a decrease in the concentration of HM in SS was studied with the use of sorbents based on CS and the complex sorbent dolomite-humate (75:25). The cleaning capacity of SS from HM increases in the series: sorbents based on waste from TPP - CS containing $\mathrm{CaCO}_{3}$ and humates (cleaning capacity E $=4.8-48.6 \%$ for dried SS and $29.3-53.3 \%$ for dehydrated SS) < sorbent based on a composition of dolomite with humate $(E=65.1-92.1 \%$ for dried and $56.6-89.4 \%$ for dehydrated SS) < a dolomite-based sorbent modified with humate $(E=90.8-99.9 \%)$. Conclusions. The maximum cleaning capacity is shown by a dolomite-based sorbent coated with a nano- and micro- sized layer of sodium humate.
\end{abstract}

KEYWORDS: sewage sludge treatment, sorbents, heavy metals, dolomite, humate, conditioned sludge.

FOR CITATION: Nazarov A.M., Tuktarova I.O., Kulagin A.A., Araslanova L.Kh., Archipenko V.A. Adsorption treatment of sewage sludge from heavy metals. Nanotechnologies in Construction. 2020; 12(5): 285-291. Available from: doi:10.15828/2075-85452020-12-5-285-291.

\section{INTRODUCTION}

A long with the development of cities and industrial centers, the volume of municipal and industrial wastewater is growing. Waste materials generated after wastewater treatment negatively affect the environment and the city's population.
Millions of tons of sewage sludge (SS) are currently accumulated on the territory of the Russian Federation. Most of its are located on the drying beds that are not equipped with waterproofing and the SS disposal mainly does not meet environmental requirements and standards accepted in the world. Accumulating near treatment facilities, SS pollute nearby territories, sur-

(c) Nazarov A.M., Tuktarova I.O., Kulagin A.A., Araslanova L.Kh., Archipenko V.A., 2020 
face water and groundwater. In this regard, the search for effective methods of SS treatment and disposal is an urgent problem.

SS contain significant amounts of heavy metals (HM), which are removed by various methods [1-8], including adsorption [9-14].

Primary treatment of SS is aimed at reducing weight, volume and disposal costs, as well as to reduce potential risks to human health during its disposal.

Sludge drying beds provide the simplest method of dewatering. Its humidity can be reduced to $75-80 \%$. Vacuum filters are most widely used for mechanical dewatering.

The main methods of cleaning SS include thermal methods, UV and microwave wave treatment. These kinds of disinfection eliminates many or all pathogenic microorganisms, but they are quite expensive and not effective against HM.

Reagent methods include SS disinfection with quicklime $(\mathrm{CaO})$. However, decontamination requires large doses (up to $30 \%$ ) and it is ineffective against HM [15].

It is known that humates are good complexing agents of HM. It binds them into stable complexes and converting into fixed water-insoluble forms [16-17].

In the paper [16] to reduce the concentration of HM in polluted soils the authors used a humic-mineral reagent based on crushed caustobiolites obtained by mixing brown or oxidized coal with $\mathrm{KOH}$ or $\mathrm{NaOH}$. This reagent contains a significant amount of humic acidsand the authors [16] found that the humic reagent reduces the concentration of $\mathrm{HM}$ in doses of $1-5 \%$ by weight in relation to the mass of soils contaminated with $\mathrm{HM}(\mathrm{Zn}, \mathrm{Mn}, \mathrm{Sr}, \mathrm{Ni}$, $\mathrm{Co}, \mathrm{Cu}, \mathrm{Pb}, \mathrm{Cd}$ ), but not effectively enough (table 1 ).

It is known that wastes from thermal power plants (TPP) - conditioned sludge (CS) are used as sorbents, which mainly consist of $\mathrm{CaCO}_{3}$ and contain up to $12 \%$ humates [18-19]. Such sorbents can be used for waste water treatment from petroleum products and HM.

In our works $[9,10,17,20-22]$, it was shown that sorbents based on dolomite, quartzite, and waste from mining and processing plants are highly effective in treating wastewater from HM.

Therefore, we have proposed a comprehensive method for cleaning SS from HM using sorbents based on dolomite, humates, and $\mathrm{CS}$ containing $\mathrm{CaCO}_{3}$ and humic compounds.

\section{METHODS AND MATERIALS}

The research object is SS - a solid fraction, that is formed as a result of the wastewater treatment process and consists of organic and mineral substances, including HM in concentrations significantly exceeding the maximum permissible standards (MPS).

As materials for the preparation of sorbents were used: - conditioned sludge, which mainly consist of $\mathrm{CaCO}_{3}$ (up to $68 \%$ ) - sorbent 1 (S1);

- composite sorbent based on dolomite and humate (25\%)- sorbent 2 (S2);

- dolomite with nano- and micro-sized layers of humates deposited on its surface (modified dolomite) sorbent 3 (S3).

Table 1

Effectiveness of soil sanitation with humic-mineral reagent

\begin{tabular}{|l|c|c|c|}
\hline \multicolumn{1}{|c|}{ Heavy metal (HM) } & $\begin{array}{c}\text { Average concentration } \\
\text { of HM in the soil before } \\
\text { sanitation, } \mathbf{m g} / \mathbf{k g}\end{array}$ & $\begin{array}{c}\text { Average concentration } \\
\text { of HM in the soil after } \\
\text { sanitation, } \mathbf{m g} / \mathbf{k g}\end{array}$ & $\begin{array}{c}\text { Effectiveness of soil } \\
\text { sanitation, \% }\end{array}$ \\
\hline Zink & 25 & 10.1 & 60 \\
\hline Manganese & 7.7 & 6.24 & 19 \\
\hline Strontium & 45.6 & 5.78 & 87 \\
\hline Nickel & 9.6 & 2.7 & 72 \\
\hline Cobalt & 9.3 & 3.66 & 61 \\
\hline Chrome & 23.7 & 5.38 & 77 \\
\hline Copper & 4.3 & 2.46 & 43 \\
\hline Lead & 34.8 & 9.32 & 73 \\
\hline Arsenic & 12 & 1.76 & 85 \\
\hline Vanadium & 8.4 & 6.18 & 26 \\
\hline Antimony & 0.7 & 0.268 & 62 \\
\hline Tin & 12.2 & 5.28 & 57 \\
\hline Cadmium & 0.99 & 0.338 & 66 \\
\hline
\end{tabular}




\section{THE RESULTS OF THE SPECIALISTS' AND SCIENTISTS' RESEARCHES}

Table 2

Chemical composition of dolomite

\begin{tabular}{|c|l|c|c|l|c|}
\hline № & \multicolumn{1}{|c|}{ Component } & $\begin{array}{c}\text { Component content, \% } \\
\text { by weight. }\end{array}$ & № & Component & $\begin{array}{c}\text { Component content, \% } \\
\text { by weight. }\end{array}$ \\
\hline 1 & $\mathrm{CaO}$ & 29.2 & 10 & $\mathrm{As}$ & $<0.002$ \\
\hline 2 & $\mathrm{SiO}_{2}$ & 2.97 & 11 & $\mathrm{~Pb}$ & $<0.005$ \\
\hline 3 & $\mathrm{Fe}_{2} \mathrm{O}_{3}$ & 12 & $\mathrm{Mn}$ & 0.021 \\
\hline 4 & $\mathrm{Al}_{2} \mathrm{O} 3$ & 0.44 & 13 & $\mathrm{Co}$ & $<0.005$ \\
\hline 5 & $\mathrm{MgO}$ & 0.45 & 14 & $\mathrm{Cu}$ & $<0.005$ \\
\hline 6 & $\mathrm{~K}_{2} \mathrm{O}$ & 21.1 & 15 & $\mathrm{Mo}$ & 0.0022 \\
\hline 7 & $\mathrm{Na}_{2} \mathrm{O}$ & 0.27 & 16 & $\mathrm{Cd}$ & $<0.001$ \\
\hline 8 & $\mathrm{~S}$ & 0.041 & 17 & $\mathrm{Cr}$ & $<0.005$ \\
\hline 9 & $\mathrm{~F}$ & $<0.005$ & 18 & $\mathrm{Hg}$ & $<0.00001$ \\
\hline
\end{tabular}

The studies were performed using $\mathrm{X}$-ray fluorescence analysis (XRF) on a VRA-30 spectrometer and inductively coupled plasma atomic emission spectrometry (ICP-AES) on an ICPE-9000 spectrophotometer with a spectral range of $167-800 \mathrm{~nm}$ and a detection limit of $1 \mathrm{mg} / \mathrm{kg}$.

The chemical composition of $\mathrm{S} 1(\%): \mathrm{SiO}_{2}-0-4.9$; $\mathrm{Fe}(\mathrm{OH})_{3}-5.8-7.1 ; \mathrm{CaSO}_{4} \cdot 2 \mathrm{H}_{2} \mathrm{O}-3-9.5 ; \mathrm{CaCO}_{3}-$ 62.8-68.2; $\mathrm{MgCO}_{3}-3.9-6.6$; organic matter - 5.2-8.9.

The concentration of HM cations ( $\%$ of weight): $\mathrm{Cu}^{2+}-0.04-0.014 ; \mathrm{Ni}^{+2}-0.008 \pm 0.003 ; \mathrm{Zn}^{2+}-0.033-$ $0.013 ; \mathrm{Mn}^{2+}-1.05-0.407 ; \mathrm{Cr}^{3+}-0.001 \pm 0.0003 ; \mathrm{Pb}^{2+}-$ $0.002 \pm 0.0003 ; \mathrm{Cd}^{2+}-0.22 \pm 0.08$.

Dolomite is a sedimentary carbonate rock of white or dark gray color. It mainly consist of the $\mathrm{Ca}$ and $\mathrm{Mg}$ carbonates class mineral. The dolomite used in the work in the form of dolomite chips (DC) - waste product of dolomite processing [23-24], the chemical composition of which is shown in table 2.

Laboratory experiments were carried out using S3, that containing $1 \%$ sodium humate deposited with a layer $200 \mathrm{~nm}-50$ microns thick [16]. $5 \mathrm{~g}$ of sorbent was added per $100 \mathrm{~g}$ of SS and actively mixed for 5 days at room temperature. As a result of this treatment, the concentrations of all the studied HM decreased to values below the MPS in the soil.

Samples of SS from the municipal unitary enterprise «Ufavodokanal» were used in the experiments. The SS previously were dewatered to a humidity of $27 \%$ at a temperature of $\sim 150^{\circ} \mathrm{C}$.

HM concentrations were determined using the ICPAES method using an ICPE-9000 spectrophotometer.

Table 3

Results of laboratory experiments and calculation of the effectiveness of reducing the concentration of HM after SS treatment with S3

\begin{tabular}{|l|c|c|c|c|}
\hline Heavy metal (HM) & $\begin{array}{c}\text { HM concentration } \\
\text { in SS before } \\
\text { cleaning, } \mathbf{~ m g / k g}\end{array}$ & $\begin{array}{c}\text { The limit values } \\
\text { for HM in the soil, } \\
\mathbf{~ m g / k g}\end{array}$ & $\begin{array}{c}\text { HM concentration } \\
\text { in SS after cleaning, } \\
\mathbf{~ m g / k g}\end{array}$ & Efficiency (E, \%) \\
\hline Lead & 550 & 130.0 & $2.3 \pm 0.7$ & 90.1 \\
\hline Cadmium & 4.32 & 2.0 & $0.11 \pm 0.03$ & 97.4 \\
\hline Zink & 1000 & 220 & $0.96 \pm 0.29$ & 99.9 \\
\hline Copper & 226 & 132.0 & $0.22 \pm 0.07$ & 99.9 \\
\hline Chrome & 130 & 6 & $4.1 \pm 1.2$ & 96.8 \\
\hline Nickel & 205 & 80.0 & $1.5 \pm 0.4$ & 99.3 \\
\hline Arsenic & 2.7 & 2.0 & $0.032 \pm 0.010$ & 98.8 \\
\hline
\end{tabular}


The effectiveness of reducing the concentration of HM in SS was calculated using the formula:

$$
\mathrm{E}=\left(\mathrm{C}_{0}-\mathrm{C}_{\mathrm{t}}\right) / \mathrm{C}_{0} \cdot 100 \% \text {, }
$$

where $\mathrm{C}_{0}, \mathrm{C}_{\mathrm{t}}$ - are the values of $\mathrm{HM}$ concentrations in SS before and after SS purification, respectively.

\section{RESULTS AND DISCUSSIONS}

We have conducted studies of sorption treatment of SS from HM in laboratory and field conditions using various types of sorbents.

The results of laboratory experiments using S3 are shown in table 3.

According to table 3, a high efficiency of reducing the concentration of HM in the SS samples was achieved and mainly amounted to $97-99.9 \%$, only for $\mathrm{Pb}$ the efficiency was $90.8 \%$.

In order to bring the experiment conditions as close as possible to the actual conditions for processing SS, field tests were conducted. The technological platform has a waterproofing base and is equipped with a drainage ditch.

Field tests were conducted in several stages:

- preparation temporary composting field for the receiving of SS;

- receiving $\mathrm{SS}$;

Two types of SS samples from the municipal unitary enterprise «Ufavodokanal» were used: dried to a humidity of $36 \%$ at a temperature of $20-30^{\circ} \mathrm{C}$ (dried SS) and dehydrated to a humidity of $27 \%$ at a temperature of $150^{\circ} \mathrm{C}$ (dehydrated SS).

\section{Table 4}

Results of field tests and calculation of the effectiveness of reducing the concentration of HM after SS treatment with a S1

\begin{tabular}{|c|c|c|c|c|c|c|}
\hline \multirow{3}{*}{$\begin{array}{l}\text { Heavy metal } \\
\text { (HM) }\end{array}$} & \multicolumn{6}{|c|}{ HM concentration in $\mathrm{SS}, \mathrm{mg} / \mathrm{kg}$} \\
\hline & \multicolumn{2}{|c|}{ Sample № 6 of dried SS } & \multirow{2}{*}{$\begin{array}{c}\text { Efficiency } \\
(\mathrm{E}, \%)\end{array}$} & \multicolumn{2}{|c|}{ Samples № 2 of dehydrated SS } & \multirow{2}{*}{$\begin{array}{c}\text { Efficiency } \\
(\mathrm{E}, \%)\end{array}$} \\
\hline & $\begin{array}{l}\text { before } \\
\text { cleaning }\end{array}$ & $\begin{array}{c}\text { after } \\
\text { cleaning }\end{array}$ & & $\begin{array}{l}\text { before } \\
\text { cleaning }\end{array}$ & $\begin{array}{c}\text { after } \\
\text { cleaning }\end{array}$ & \\
\hline Copper & $226 \pm 57$ & $215 \pm 54$ & 4.8 & $158 \pm 40$ & $108 \pm 23$ & 31.6 \\
\hline Zink & $1000 \pm 250$ & $630 \pm 160$ & 37.0 & $430 \pm 110$ & $304 \pm 64$ & 29.3 \\
\hline Iron & $13900 \pm 3500$ & $18000 \pm 5000$ & - & $11985 \pm 3020$ & - & - \\
\hline Calcium & $41000 \pm 10000$ & $34000 \pm 9000$ & 17.0 & $16000 \pm 4000$ & $41000 \pm 10000$ & - \\
\hline Manganese & $560 \pm 140$ & $320 \pm 80$ & 42.8 & $300 \pm 80$ & - & - \\
\hline Nilel & $79 \pm 20$ & $60 \pm 15$ & 24.0 & $60 \pm 15$ & $28 \pm 8$ & 53.3 \\
\hline Cadmium & $14.0 \pm 3.5$ & $7.2 \pm 2.3$ & 48.6 & $16.0 \pm 4.0$ & 10.0 & 37.5 \\
\hline Lead & $25.0 \pm 6.2$ & $14 \pm 4.0$ & 44.0 & - & - & - \\
\hline
\end{tabular}

Table 5

Results of field tests and calculation of the effectiveness of reducing the concentration of HM after treatment of SS with a S2

\begin{tabular}{|c|c|c|c|c|c|c|}
\hline \multirow{3}{*}{$\begin{array}{l}\text { Heavy metal } \\
\text { (HM) }\end{array}$} & \multicolumn{6}{|c|}{$\mathrm{HM}$ concentration in $\mathrm{SS}, \mathrm{mg} / \mathrm{kg}$} \\
\hline & \multicolumn{2}{|c|}{ Sample № 6 of dried SS } & \multirow{2}{*}{$\begin{array}{c}\text { Efficiency } \\
(\mathrm{E}, \%)\end{array}$} & \multicolumn{2}{|c|}{ Samples № 2 of dehydrated SS } & \multirow{2}{*}{$\begin{array}{c}\text { Efficiency } \\
(\mathrm{E}, \%)\end{array}$} \\
\hline & $\begin{array}{l}\text { before } \\
\text { cleaning }\end{array}$ & $\begin{array}{c}\text { after } \\
\text { cleaning }\end{array}$ & & $\begin{array}{l}\text { before } \\
\text { cleaning }\end{array}$ & $\begin{array}{c}\text { after } \\
\text { cleaning }\end{array}$ & \\
\hline Copper & $226 \pm 57$ & $79 \pm 20$ & 65.1 & $158 \pm 40$ & $38 \pm 9.5$ & 75.9 \\
\hline Zink & $1000 \pm 250$ & $114 \pm 28$ & 88.6 & $430 \pm 108$ & $125 \pm 32$ & 70.9 \\
\hline Nikel & $79 \pm 20$ & $23.3 \pm 5.8$ & 70.5 & $60 \pm 15$ & $26.1 \pm 5.0$ & 56.6 \\
\hline Cadmium & $14 \pm 4.2$ & $1.1 \pm 0.2$ & 92.1 & $16 \pm 4.0$ & $1.7 \pm 4.2$ & 89.4 \\
\hline Lead & $89 \pm 22$ & $67 \pm 16$ & 24.7 & $14 \pm 3.5$ & $6.2 \pm 1.6$ & 52.0 \\
\hline Arsenic & $2.7 \pm 0.7$ & $1.5 \pm 0.4$ & 44.4 & $2.7 \pm 6.7$ & $1.7 \pm 4.2$ & 30.8 \\
\hline
\end{tabular}


- treatment of S1 and S2: mixing SS with sorbents 3-4 times within 4-5 days;

- sampling of treated SS and determination of HM concentrations in them by the ICR-AES method (table 4).

According to table 4, the using of S1 reduces the content of $\mathrm{Zn}, \mathrm{Mn}$, and $\mathrm{Ni}$, but increases the concentrations of $\mathrm{Fe}$ and $\mathrm{Ca}$ and generally does not show high efficiency (4.8-48.6\% for dried SS and 29.3-53.3\% for dehydrated $\mathrm{SS})$. The concentration of $\mathrm{Fe}$ and $\mathrm{Ca}$ increases due to their presence in the CS.

Table 5 shows the results of field tests using a S2.

The efficiency of SS treatment using a S2 sorbent from $\mathrm{Zn}, \mathrm{Cu}, \mathrm{Ni}, \mathrm{Cd}$ at room temperature is $65.1-92.1 \%$ for dried sludge and $56.6-89.4 \%$ for dehydrated sludge, for $\mathrm{Pb}$ and $\mathrm{As}-24.7-44.4 \%$ and $52.0-30.8 \%$, respectively (table 5).

Thus, comparing the results of tables 4 and 5, sorbents based on the composition of dolomite and humate showed higher efficiency of SS treatment than sorbents based on CS.

It should be noted that the efficiency of SS treatment with S2 and S3 decreases in the field experiments that in laboratory experiments, despite the fact that the humate concentration in the $\mathrm{S} 3$ was $1 \%$, and in the $\mathrm{S} 2-25 \%$ in relation to dolomite. This may be due to less efficient mixing of the S2 with SS in the field conditions. The relative efficiency of sorbents in the process of SS treatment from heavy metals increases in the series: $\mathrm{S} 1<\mathrm{S} 2<\mathrm{S} 3$.

\section{CONCLUSIONS}

Laboratory and field experiments were carried out to study the efficiency of SS treatment with sorbents based on waste from TPP and humic sorbents (based on dolomite and sodium humates) from heavy metals $-\mathrm{Cu}, \mathrm{Zn}$, $\mathrm{Ni}, \mathrm{Cd}, \mathrm{Pb}, \mathrm{As}, \mathrm{Cr}$.

It was found that the efficiency of treatment increases in the following series: sorbents based on waste from TPP - CS (containing $\mathrm{CaCO}_{3}$ and humates - treatment efficiency $\mathrm{E}=4.8-48.6 \%$ for dried SS and $29.3-53.3 \%$ for dehydrated SS) < sorbent based on a composition of dolomite with humate ( $25 \%$ sodium humate, $\mathrm{E}=65.1-$ $92.1 \%$ for dried SS and $56.6-89.4 \%$ for dehydrated SS) < sorbent based on modified dolomite (1\%, layer $200 \mathrm{~nm}-$ 50 microns, $\mathrm{E}=90.8-99.9 \%$ ).

A method for treatment of SS at water utilities and industrial enterprises based on humic sorbents is proposed.

\section{REFERENCES}

1. Belyuchenko I.S. Sewage sludge, decontamination and use of. The North Caucasus Ecological Herald. 2016;12 (1): 82-95.

2. Dmitrieva T.V. Types of precipitation and modern methods of water purification. Vector of Geosciences. 2018;1(4): $42-47$.

3. Novikova O.K. Treatment of sewage sludge. Gomel: Belgut; 2015.

4. Budykina T.A. Processing of sewage sludge. Moscow: Creative economy; 2012.

5. Volkov D.A., Chirikov A.Yu., Buravlev I.Yu., Yudakov A.A. Multicomponent inorganic wastewater purification from $\mathrm{Cu}^{2+}, \mathrm{Zn}^{2+}, \mathrm{Ni}^{2+}, \mathrm{Cr}^{3+}, \mathrm{Pb}^{2+}, \mathrm{Fe}^{2+}$ cations, including sludge utilization. Vestnik of Far Eastern Branch of Russian Academy of Sciences. 2019;6(208): 113-123. Available from: doi: 10.25808/08697698.2019.208.6.012.

6. Balakirev V.F., Aksenov V.I., Nichkova I.I., Krymsky V.V. Treatment of aggressive industrial effluents. Moscow: Russian Academy of Sciences; 2019.

7. Reshetov N.G., Oleynik A.S. Problems of treatment and utilization of sewage sludge. In: Proceedings of Voronezh State University. Series: Geography. Geoecology. 2001;1: 114-116.

8. Stepanov E.G., Tuktarova I.O., Malikova T.Sh. Problems of placement of industrial wastes in landfills in the industrial city. Nanotechnologies in Construction. 2017;9 (2): 103-118. Available from : doi: 10.15828/2075-8545-20179-2-103-118. (In Russian).

9. Araslanova L.Kh, Kuznetsova E., Tuktarova I.O., Nazarov A.M. Development of oil product contaminated wastewater treatment technology using sorbents based on mining waste. In: International Conference on Efficient Production and Processing (ICEPP-2020), Prague, Czech Republic; E3S Web of Conferences, Volume 161. Available from: doi: 10.1051/e3sconf/202016101030. (In English). 
10. Araslanova L.Kh., Salmanova E.R., Solovyeva E.A., Larkina, A.A., Tuktarova I.O., Nazarov A.M. Research of effectiveness of natural and modified sorbents for wastewater treatment based on mica quartzite treatment waste. Nanotechnologies in Construction. 2019;11(1): 106-116. Available from: doi: 10.15828/2075-8545-2019-11-1-106-116. (In Russian).

11. Zhumamurat M.S., Ahmetova A.B. Choice of naturalsorbents for sewage treatment. Relevant scientific research in the modern world. 2017;1-3(21): 116-125.

12. Kakhramanov N.T., Gadzhieva R.Sh.G., Guliev A.M., Agaguseinova M.M.G. Current state of problem of sorptionwater treatment from heavy metals. Water: chemistry andecology. 2013; 6(60): 40-52.

13. Malkin P. Wastewater treatment from heavy metal ions usingnanoactivated complexes of natural zeolite and diatomite. Nanotechnologies in Construction. 2018;10(2): 21-41. Available from: doi: 10.15828/2075-8545-2018-10-2-21-41.

14. Hlynina N.G., Aleksejko I.S. Studying of sorption properties of sorbents in static conditions. Bulletin of the Krasnoyarskstate agricultural university. 2008;1: 92-99.

15. Scherbakov V.I., Pomogayeva V.V., Sukhov S.S. Limeapplication as way of disinfecting of the deposit of sewage. Russian Engineer. 2016; 2(5): 32-37.

16. Shul'gin A.L., Shul'gin A.A. Humine-mineral reagent and method for its preparing, method for sanitation of polluted soil, method for detoxification of output waste and processing mineral resources and recultivation of mountain rock dampand tail-storing, method for treatment of sewage waters and method for utilization of deposits. Russian Federation Patent 2233293. 27.07.2004.

17. Nazarov A.M., Latypova F.M., Araslanova L.Kh.,Sal'manova E.R., Tuktarova I.O. Research of efficiency ofnatural and modified sorbents for purification of industrial sewage from heavy metal ions. Nanotechnologies in Construction. 2018;10(5): 125-143. Available from: doi: 10.15828/2075-8545-2018-10-5-125-143.

18. Nikolaeva L.A., Nedzvetskaya R.Ya. Purification of effluent waters from industrial enterprises using a biosorption technology. Thermal Engineering. 2012;59 (3): 258-260.

19. Nikolaeva L.A., Shigabutdinova A.F. Resource-saving technology of waste water purification from heavy metals ions by sludge of water treatment TPP. Energy saving and water treatment. 2013;4: 13-15. (In Russian).

20. Araslanova L.Kh., Kuznetsova E., Tuktarova I.O., Nazarov A.M. Development of oil product contaminated waste water treatment technology using sorbents based on mining waste. International Conference on Efficient Production and Processing (ICEPP-2020)]. Prague, 2020; Vol. 161. Available from: https://doi.org/10.1051/e3sconf/202016101030.

21. Bikulova V.Zh., Latypova F.M., Mukhametdinova L.Kh. Adsorption cleaning of industrial waste water from zinc ion. Water: chemistry and ecology. 2013;3: 37-39.

22. Salmanova E.R., Nazarov A.M., Tuktarova I.O. Receiving Composite Sorbents for Sewage Treatment on the Basis of Waste of Production and Processing of Micaceous Quartzite. In: Materials Engineering and Technologies for Production and Processing V. $5^{\text {th }}$ International Conference on Industrial Engineering (5 $5^{\text {th }}$ ICIE 2019). Solid State Phenomena, 2020;299: 49-54. Available from: doi: 10.4028/www.scientific.net/SSP.299.49.

23. Kalyukova E.N. Buzaeva M.V., Klimov E.S. Sorption properties of natural sorbents - silica clay and magnesite inrelation to sulphatic ions. Bashkir chemical journal. 2010;2: 139-141.

24. Nefedyeva T.A. Blagoveshchenskya N.V. Comparison of the sorption properties of native and thermally the modified dolomite in relation to the iron cations. Sorption chromatographic processes. 2017;3: 429-435. 


\section{INFORMATION ABOUT THE AUTHORS}

Alexey M. Nazarov, Doctor of Chemistry, Professor of the Department «Environmental Protection and Prudent Exploitation of Natural Resources», Ufa State Petroleum Technological University, Ufa, Bashkortostan Republic, Russia, ORCID: https://orcid.org/0000-0002-1164-2573, e-mail: nazarovam1501@gmail.com

Iren O. Tuktarova, Ph.D. in Engineering, Professor, Head of Department «Environmental Protection and Prudent Exploitation of Natural Resources», Ufa State Petroleum Technological University, Ufa, Bashkortostan Republic, Russia, ORCID: https://orcid.org/0000-0003-4731-1394, e-mail: umrko@mail.ru

Andrey A. Kulagin, Doctor of Biological Sciences, Head of the Department of Ecology, Geography and Nature Management, Bashkir State Pedagogical University named after M. Akmulla, Ufa, Bashkortostan Republic, Russia, ORCID: https://orcid.org/0000-0003-3107-1904, e-mail: kulagin-aa@mail.ru

Lyaisan Kh. Araslanova, Assistant of the Department «Environmental Protection and Prudent Exploitation of Natural Resources», Ufa State Petroleum Technological University, Ufa, Bashkortostan Republic, Russia, ORCID: https://orcid.org/0000-0003-1273-0927, e-mail: lyaysan-86@yandex.ru

Vasily A. Archipenko, $1^{\text {st }}$ category specialist, LUKOIL-Uralnefteprodukt, Ufa, Bashkortostan Republic, Russia, ORCID: https://orcid.org/0000-0001-6354-5559, e-mail: bacek-2308@ya.ru.

\section{Authors declare the absence of any competing interests.}

Received: 07.09.2020.

Revised: 02.10.2020.

Accepted:03.10.2020. 